\title{
Effect of atmospheric circulation on recent temperature changes in Finland
}

\author{
Jouni Räisänen ${ }^{1}$ (D)
}

Received: 11 January 2019 / Accepted: 2 July 2019 / Published online: 8 July 2019

(c) The Author(s) 2019

\begin{abstract}
The effect of atmospheric circulation on temperature variability and trends in Finland in 1979-2018 is studied using a trajectory-based method. On the average $81 \%$ of the detrended interannual variance of monthly mean temperatures is explained by the start points of the three-dimensional trajectories, with the best performance in autumn and winter. Atmospheric circulation change is only found to have had a small impact on the observed annual mean temperature trends, but it has considerably modified the trends in individual months. In particular, changes in circulation explain the lack of observed warming in June, the very modest warming in October in southern Finland, and about a half of the very large warming in December. The residual trends obtained by subtracting the circulation-related change from observations are robustly positive in all months of the year, exhibit a smoother seasonal cycle, and agree better with the multi-model mean temperature trends from models in the 5th Coupled Model Intercomparison Project (CMIP5). Nevertheless, some differences between the residual trends and the average CMIP5 trends are also found.
\end{abstract}

Keywords Atmospheric circulation $\cdot$ Trajectory $\cdot$ Temperature $\cdot$ Climate change $\cdot$ Finland $\cdot$ CMIP5

\section{Introduction}

The observed evolution of climate results from the interplay of two factors. On one hand, climate is affected by changes in external forcing on different time-scales (e.g., anthropogenic increases in greenhouse gas concentrations and variations in stratospheric aerosol load due to volcanic eruptions). On the other hand, the non-linear dynamics of the climate system generate substantial internal variability. A separation between forced change and internal variability would be valuable, for example, when testing climate models for their ability to simulate climate response to increasing greenhouse gas concentrations.

The effects of external forcing and internal variability can be approximately separated in single-model ensembles of

Electronic supplementary material The online version of this article (https://doi.org/10.1007/s00382-019-04890-2) contains supplementary material, which is available to authorized users.

Jouni Räisänen

jouni.raisanen@helsinki.fi

1 Institute for Atmospheric and Earth System Research/ Physics, Faculty of Science, University of Helsinki, P.O. Box 64, 00014 Helsinki, Finland climate model simulations, in which the ensemble members share the same external forcing but have different realizations of internal variability (e.g., Selten et al. 2004; Deser et al. 2012, 2014). Averaging over a sufficient number of ensemble members, internal variability largely cancels out, leaving a good approximation of the externally forced climate change. However, this method is not applicable to the real world, where only one realization of climate is available.

Since atmospheric greenhouse gas concentrations have increased gradually over a period of several decades, the resulting forced climate change should also be a smooth function of time, assuming that this forced response is approximately linear (Tebaldi and Arblaster 2014). Conversely, a large fraction of internal variability occurs on relatively short, interannual-to-decadal time-scales. Therefore, calculating trends over a sufficiently long period of time helps to better discern the anthropogenic climate change signal. Still, on local to regional scales, internal climate variability may substantially affect even multi-decadal trends in climate (Deser et al. 2012, 2014). This holds even for surface air temperature, which generally has a higher signal-to-noise ratio between the greenhouse gas induced change and internal variability than, for example, precipitation and sea level pressure (Räisänen 2001; Deser et al. 2012). 
A major cause of surface climate variability is variation in atmospheric circulation (Parker 2009; Deser et al. 2012, 2014; Saffioti et al. 2016, 2017). For example, surface air temperature is affected by circulation both directly via the advection/energy convergence mechanism and because circulation impacts diabatic heating, particularly by regulating cloudiness (Holmes et al. 2016; Räisänen 2018). Thus, isolating the effect of atmospheric circulation might help to better delineate the underlying long-term anthropogenic climate change that would have occurred without the change in circulation (Saffioti et al. 2016).

To complicate the matter, atmospheric circulation may change as part of forced anthropogenic climate change as well as a result of internal variability. For example, Saffioti et al. (2017) analysed an ensemble of climate model simulations from the 5th Coupled Model Intercomparison Project CMIP5 (Taylor et al. 2012) for the Representative Concentration Pathways (RCP) 8.5 scenario, and found that $13 \%$ of the 40-model mean winter warming in Scandinavia in the years 2006-2050 was explained by atmospheric circulation change. Nevertheless, circulation changes in climate models tend to have a low signal-to-noise ratio, becoming robust only when averaged over a large number of model simulations (see also Selten et al. 2004 and Deser et al. 2012). To the extent that these model results serve as a guide for reality, this leads to the hypothesis that most of the atmospheric circulation changes observed during the past few decades have resulted from internal variability rather than from external forcing.

A wide range of statistical methods have been used to describe the effect of atmospheric circulation on surface climate variability; examples are listed in the introductions of Smoliak et al. (2015) and Saffioti et al. (2016). These methods all share the premise that, in a stationary climate, a similar atmospheric circulation should be associated with similar surface climate conditions. However, they differ in several aspects of their formulation. One of the main choices is the variables used to describe the circulation. Sea level pressure is probably the most common choice, but geopotential heights or winds at higher atmospheric levels can also been used (e.g., Klein and Walsh 1983). Another choice is the time resolution of these predictor variables. When the interest is on interannual climate variability, monthly mean data are commonly used. However, some studies have used daily data (e.g., Fereday et al. 2018; Gallagher et al. 2018), which give potentially more robust information on the relationship between circulation and surface climate by providing a larger sample size. Finally, a variety of approaches have been used for characterizing the statistical dependence of surface climate on the pressure or height fields that describe the circulation. Most of these fall within the families of regression and analog methods. Examples of the former include ordinary linear regression using either indices of large-scale circulation variability [such as the North Atlantic Oscillation index in Karpechko et al. (2015)] or multiple principal components of the pressure or height field as predictors (e.g., Saffioti et al. 2016, 2017), as well as partial least squares regression (Smoliak et al. 2015). Analog methods have been based on objective classification of pressure patterns (e.g., Gallagher et al. 2018) or other measures of similarity (e.g., Cattiaux et al. 2010), and on the constructed analogue technique (Deser et al. 2016; Lehner et al. 2017).

In this study, we aim to quantify the effect of atmospheric circulation on temperature variability and trends in Finland in the years 1979-2018. We build on Parker (2009), who related variations of Central England temperature to air mass origin using a trajectory-based method. Such a trajectorybased approach has at least two attractive features. First, the geographical origin of air is directly related to the likely effect of temperature advection, particularly in seasons with a strong climatological temperature gradient. Second, backtrajectories implicitly account for the fact that temperature at any given time is affected by the atmospheric circulation in the preceding days as well as the concurrent circulation. Nevertheless, we extend the method of Parker (2009) in two important ways:

1. Three-dimensional instead of horizontal trajectories are used. This improves the performance of the method particularly during the warm season.

2. Trajectories with different durations (24-168 h) and end levels (550-1000 hPa) are considered. Combining the information from the various alternatives turns out to provide a better description of temperature variability than any single duration/end level combination alone.

In hydrostatic balance, increasing temperature reduces the vertical derivative of pressure and thus causes a systematic increase in geopotential height at constant pressure levels above the surface (Toumi et al. 1999). However, wind and therefore trajectories are governed by the horizontal gradient rather than the absolute value of geopotential height. Because of this, a trajectory-based description of circulation is much less affected by greenhouse gas induced global warming than a method based directly on atmospheric geopotential heights would be. In addition, time series are detrended in this study when analyzing the relationship between circulation and temperature (Sect. 2).

The methods and the data sets used are documented in Sect.2. The observed temperature trends in Finland and the results of the trajectory-based analysis are described in Sect. 3. Then, in Sect. 4, the observed temperature trends with and without the circulation effect subtracted are compared with the temperature trends found in the CMIP5 
simulations. Finally, the main conclusions are given in Sect. 5. Several additional figures are provided as supplementary material.

\section{Methods}

We relate daily mean surface air $(2 \mathrm{~m})$ temperatures from the European Climate Assessment \& Dataset gridded E-OBS dataset version 19.0e (Haylock et al. 2008) to trajectories calculated from 6-hourly horizontal wind components and vertical motion $(\omega)$ in the ERA-Interim reanalysis (Dee et al. 2011). The E-OBS data are averaged over two $1^{\circ}$ latitude $\times 2^{\circ}$ longitude boxes: region South in southern $\left(61^{\circ}-62^{\circ} \mathrm{N}, 23^{\circ}-25^{\circ} \mathrm{E}\right)$ and region North in northern Finland $\left(67^{\circ}-68^{\circ} \mathrm{N}, 26^{\circ}-28^{\circ} \mathrm{E}\right)$ (Fig. 2). Due to the large horizontal scale of monthly and longer term temperature variability, the precise delineation of these regions is unimportant (for example, qudrapling of their area had virtually no effect on the results). The ERA-Interim data have a higher native resolution but were reduced to a $50 \mathrm{hPa}$ vertical and $2.5^{\circ} \times 2.5^{\circ}$ horizontal grid to cut down the data volume. The study covers the years 1979-2018.

To put the observed temperature trends in context, global climate model simulations from CMIP5 are used in Sect. 4. Temperature trends in the two study areas are calculated for the same set of 42 CMIP5 models as used in the Intergovernmental Panel on Climate Change 5th assessment report (Collins et al. 2013), concatenating the historical simulations for 1979-2005 with RCP4.5 simulations for 2006-2018. Since the four RCP scenarios are still close to each other in the early 21 st century, the choice between them is largely arbitrary (van Vuuren et al. 2011).

Parker (2009) calculated geostrophic winds from sea level pressure, used them to trace the origin of air masses arriving to Central England, and in this way identified the component of temperature variability associated with atmospheric circulation. For the current study, his method was modified and extended in several ways. First, back-trajectories were calculated from seven end levels, $550-1000 \mathrm{hPa}$, at $75 \mathrm{hPa}$ intervals. Second, the calculation was based on analyzed rather than geostrophic winds, and vertical motion was included. Third, the method of relating temperature anomalies to trajectory origin was revised. The details are described below.

Back-trajectories ending in the centres of the two study areas $\left(61.5^{\circ} \mathrm{N}, 24^{\circ} \mathrm{E}\right.$ and $\left.67.5^{\circ} \mathrm{N}, 27^{\circ} \mathrm{E}\right)$ at each of the seven levels were calculated four times per day $(00,06,12$ and 18 UTC). Wind and vertical motion were interpolated linearly between the longitudes, latitudes, pressure levels and times included in the reanalysis, and the air parcels were then traced back using a 10-min time step. The start coordinates of the trajectories were registered for seven trajectory durations: 24, 48, 72, 96, 120, 144 and $168 \mathrm{~h}$.
For each end day and each trajectory duration, the coordinates of the 00, 06, 12 and 18 UTC trajectories were averaged before relating them to the daily mean temperature anomaly in the E-OBS data set.

The dependence of temperature on the coordinates of the trajectory origin was estimated using regression analysis. First, the coordinates were transformed to a rotated grid in which the centre of the southern or northern target area is at $\left(0^{\circ} \mathrm{N}, 0^{\circ} \mathrm{E}\right)$. Then the coefficients in the linear regression equation:

$\Delta T_{\text {day }}=a_{0}+\sum_{i=1}^{N} a_{i} f_{i}+\varepsilon$

were determined using the least squares method. Here $\Delta T_{\text {day }}$ is the anomaly in daily mean temperature relative to the 40-year (1979-2018) mean for the same day and $N=19$ is the number of predictors. The predictors $f_{i}$ are first- $(x, y$, $z)$, second- $\left(x^{2}, y^{2}, z^{2}, x y, x z, y z\right)$ and third-order $\left(x^{3}, y^{3}, z^{3}\right.$, $\left.x^{2} y, x y^{2}, x^{2} z, y^{2} z, x z^{2}, y z^{2}, x y z\right)$ functions of $x, y$ and $z$, which are defined as follows: $x=\sin (\lambda) \cos (\varphi), y=\sin (\varphi)$, and $z=\Delta p$. Here $\lambda$ and $\varphi$ are the longitude and latitude of the trajectory start point in the rotated grid, and $\Delta p$ is the pressure difference between the trajectory start and end points. These formulations allow $x$ and $y$ to change nearly linearly with distance for short trajectories, while simultaneously avoiding spuriously large far-field values and discontinuities that would result from using $\lambda$ and $\varphi$ directly. The coefficients $a_{0} \ldots a_{N}$ were estimated separately for each 12 calendar months. Examples of the resulting regression fields are shown in Fig. S1.

The focus in this paper is on monthly temperature anomalies. The simplest way to estimate their circulationrelated component is to average the daily anomalies from (1):

$\Delta T_{1}={\overline{a_{0}+\sum_{i=1}^{N} a_{i} f_{i}}}^{\text {MON }}$

where the over bar indicates a time mean. However, although $\Delta T_{1}$ and the observed monthly temperature anomalies $\Delta T_{\mathrm{obs}}$ are in many cases highly correlated, $\Delta T_{1}$ severely underestimates the amplitude of the anomalies. Furthermore, the residuals $\Delta T_{\mathrm{obs}}-\Delta T_{1}$ exhibit a systematic positive correlation with $\Delta T_{1}$ itself (see Fig. 1 for an example). Therefore, revised estimates for the monthly temperature anomalies were derived by using $\Delta T_{1}$ as the predictor:

$\Delta T_{2}=b_{0}+b_{1} \Delta T_{1}$. 

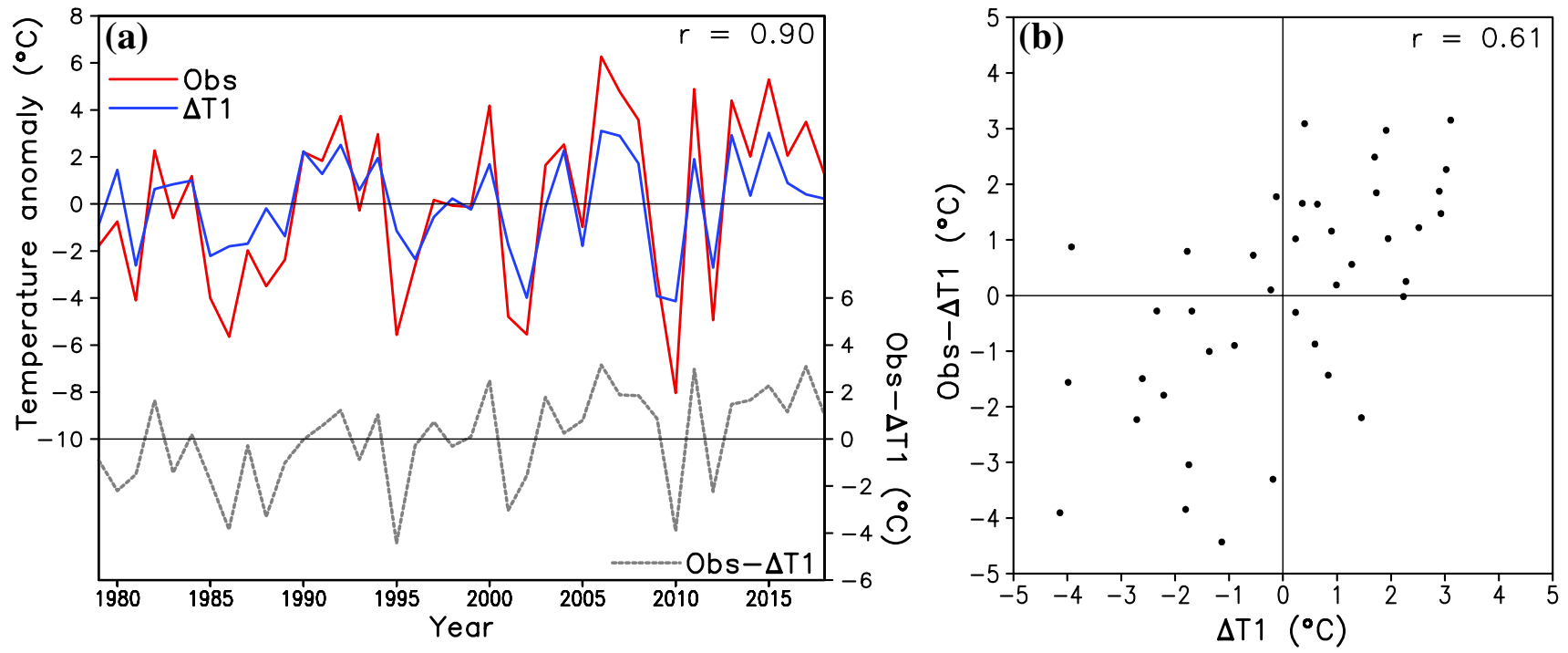

Fig. 1 a Anomalies of December mean temperature in area South from observations (red) and the estimate $\Delta \mathrm{T}_{1}$ from Eq. (2) (blue), using 96-hour trajectories ending at $850 \mathrm{hPa}$. The resid-

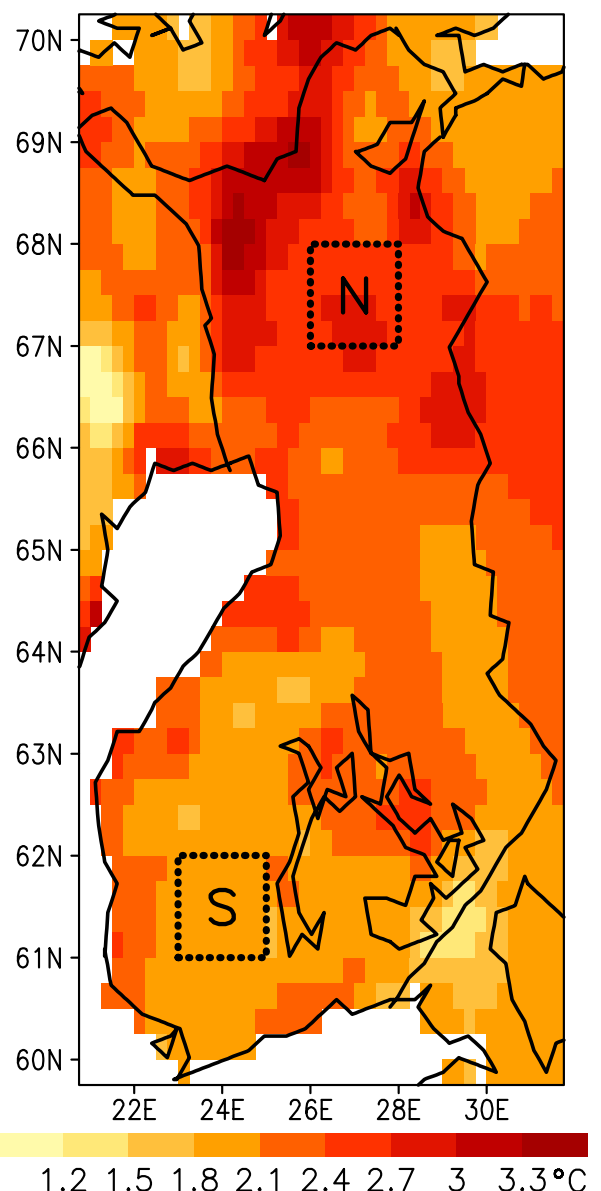

Fig. 2 Linear trends in annual mean temperature in Finland from 1979 to 2018 in the E-OBS data set. The areas South (S) and North $(\mathrm{N})$ are also indicated ual $\Delta \mathrm{T}_{\text {obs }}-\Delta \mathrm{T}_{1}$ (gray) is shown at the bottom. b The relationship between $\Delta \mathrm{T}_{1}$ and $\Delta \mathrm{T}_{\text {obs }}-\Delta \mathrm{T}_{1} \cdot r=$ correlation coefficient

The values of $b_{1}$ vary with month, trajectory end level and trajectory duration but almost invariably exceed one. For the case in Fig. $1, b_{1} \approx 1.5$, which is typical. ${ }^{1}$ There are at least two potential explanations for this result. First, monthly means of temperature may be more sensitive to atmospheric circulation than daily mean temperatures, because temperature variations on the daily time scale are more strongly damped by the surface heat capacity. Second, uncertainties in the trajectory calculation introduce noise to the predictors on the right-hand-side of (1), which makes the least-squares regression coefficients for daily temperature variability smaller than they would be in the absence of noise. On the monthly time scale, most of the noise cancels out, allowing $b_{1}$ in (3) to exceed one.

The trajectory duration (24-168 h) and end level (550-1000 hPa) are both somewhat arbitrary choices. In general, medium-long $(72-120 \mathrm{~h})$ trajectories ending at midlevels (700-850 hPa) are found to give the smallest regression residuals, but this minimum is not sharp (Fig. S3). Therefore, a consensus estimate for the circulation-related monthly temperature anomaly is calculated as

$\Delta T_{3}=c_{0}+c_{1}\left\langle\Delta T_{2}\right\rangle$

where the brackets indicate averaging over all the 49 (duration, end level) combinations and the coefficients $c_{0}$ and $c_{1}$ are estimated from linear regression against $\Delta T_{\text {obs. }}$.

\footnotetext{
${ }^{1} b_{0}$ is small but differs from zero because the regression is applied in a leave-1-out mode, so that the mean temperature anomaly in the sample used for calculating the coefficients is not exactly zero.
} 


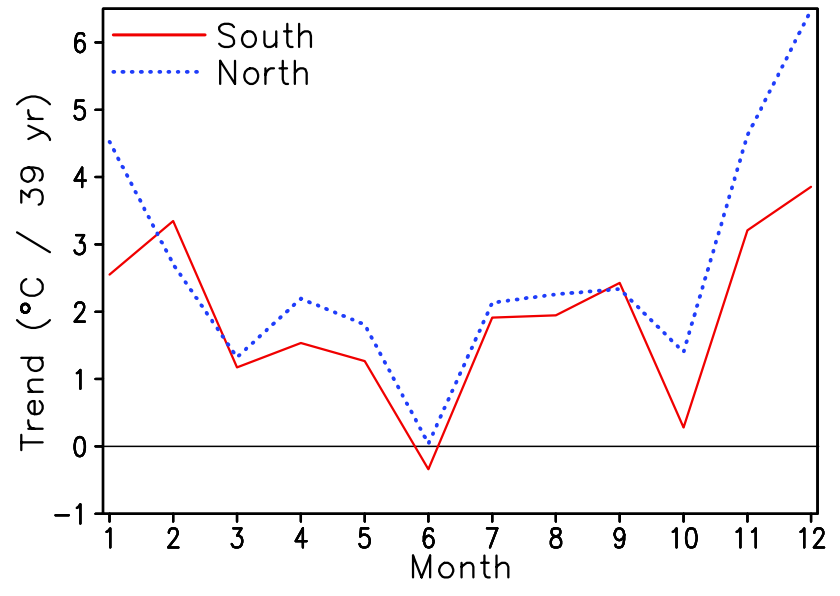

Fig. 3 Linear trends in monthly mean temperature from 1979 to 2018 in (red) South and (blue) North

In all of (1), (3) and (4), the regression coefficients were calculated separately for each year, using only the data for the other 39 years. Thus, the predicted temperature anomalies are independent from the observed temperature anomaly. Furthermore, the predictor and predictand time series were linearly detrended when deriving the regression coefficients. These choices serve to minimize both artificial skill in the regression and the aliasing between circulation-related variability and noncirculation-related climate change.

(a) South

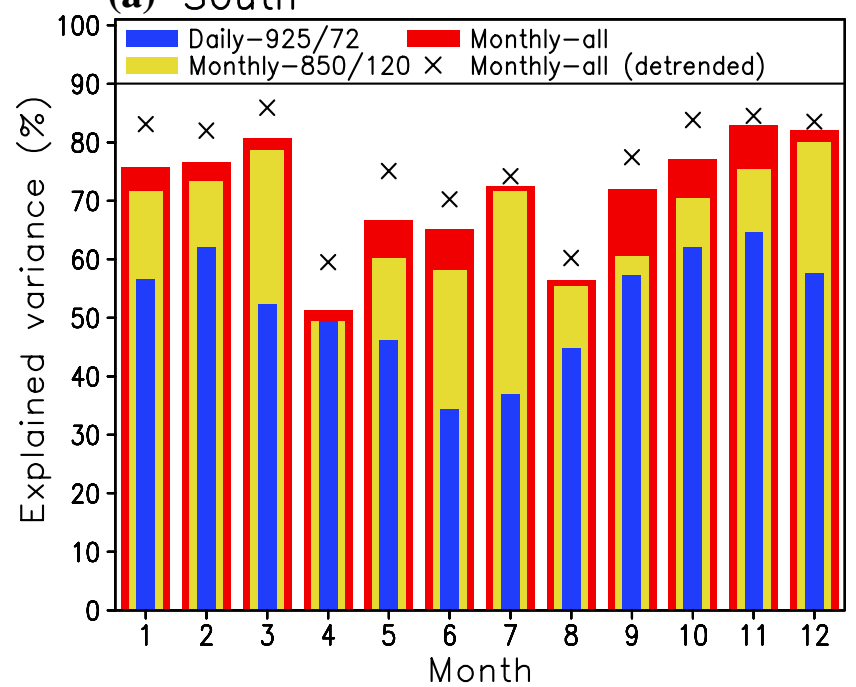

Fig. 4 Explained variance of temperature anomalies for a South and b North. Blue and yellow: daily and monthly anomalies, using the best duration - end level combination for each; red: monthly anoma-

\section{Results}

In this section, the observed temperature trends in the study area are first described (Sect. 3.1). Then, the ability of the trajectory-based approach to explain interannual temperature variability is documented (Sect. 3.2). After this, the resulting estimates of circulation-induced temperature trends are presented (Sect. 3.3) and their meteorological interpretation is studied (Sect. 3.4).

\subsection{Temperature trends in Finland}

In the years 1979-2018, the annual mean temperature increased everywhere in Finland (Fig. 2a). The 39-year linear trends in the E-OBS data set vary from $1.3{ }^{\circ} \mathrm{C}$ near the southeastern border to $3.5^{\circ} \mathrm{C}$ in northwestern Lapland, although some of the local variability might reflect inhomogeneity in the underlying station observations. The average trends in areas South $\left(1.9^{\circ} \mathrm{C}\right)$ and North $\left(2.7^{\circ} \mathrm{C}\right)$ are fairly representative for southern and northern Finland.

The observed temperature trends vary from month to month, with generally smaller warming in summer than in winter (Fig. 3). In particular, June mean temperatures have slightly decreased in South and remained nearly constant in North. There is also a distinct local minimum in warming in October in South, between larger warming in September and November. By contrast, a sharp maximum in warming occurred in December particularly in North, with a 39-year trend of $6.5^{\circ} \mathrm{C}$. It is tempting to hypothesize that at least some of these irregularities in the observed temperature

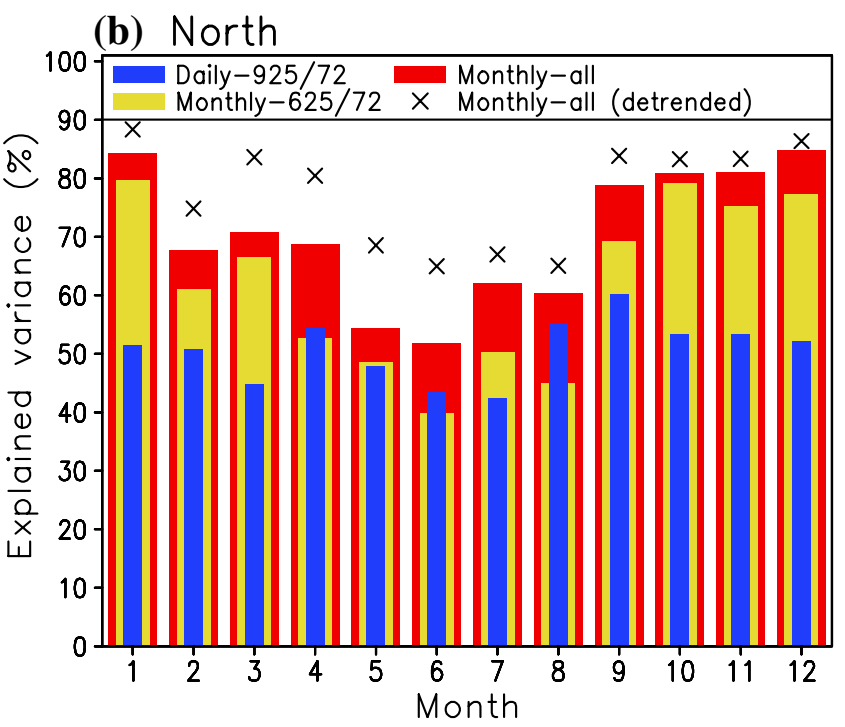

lies, consensus model, crosses: linearly detrended monthly anomalies, consensus model 
Table 1 Explained annual mean variance of temperature anomalies (\%) 1979-2018

\begin{tabular}{lll}
\hline & South & North \\
\hline Daily, best level/duration (S: 925/72, N: 925/72) & 55.5 & 50.9 \\
Monthly, best level/duration (S: 850/120, N: 625/72) & 72.1 & 68.5 \\
Monthly, consensus model & 76.0 & 75.3 \\
Monthly, detrended, consensus model & 81.0 & 80.8 \\
Monthly, detrended, consensus model, only 1st order terms & 73.3 & 75.7 \\
Monthly, detrended, consensus model, 1st +2nd order terms & 80.3 & 79.8 \\
Monthly, detrended, consensus model, only horizontal terms & 76.2 & 75.9 \\
\hline
\end{tabular}

trends have been caused by changes in the atmospheric circulation.

\subsection{Performance of the regression model}

In Fig. 4, the performance of the trajectory-based regression is measured by the explained variance

$E=1-\frac{{\overline{\Delta T_{\mathrm{res}}^{2}}}^{1979-2018}}{\frac{\Delta T_{\mathrm{obs}}^{2}}{1979-2018}}$

where $\Delta T_{\text {res }}$ is the difference between the observed and predicted temperature anomalies. Four general conclusions hold for both the southern and the northern area. First, the explained variance is typically larger for monthly than daily mean temperatures (yellow vs. blue bars). Second, monthly and to some extent daily temperature variability is predicted better in autumn, winter and early spring (September to March/April) than in late spring and summer (April/May to August). This aligns with the results of Parker (2009) and is most likely explained by the larger climatological temperature gradient in the first-mentioned seasons. Third, the consensus model (4) almost invariably outperforms the best single-level/single-duration model (3) (red vs. yellow bars), when the latter is chosen based on the explained annually averaged variance. Even when the best single-level/singleduration model is selected separately for each month, which clearly involves a risk of over-fitting (DelSole and Shukla 2009), the consensus model is still better in about half of all cases (not shown). Finally, detrending of the time series for 1979-2018 increases the explained variance (crosses vs. red bars). This suggests that atmospheric circulation has caused a larger fraction of the interannual variability than of the long-term trends of temperature in Finland.

Statistics for explained annually averaged variance are given in Table 1; note that these values are affected most by winter months when temperature variability in Finland is largest. For the monthly mean temperature anomalies, the best single-level/single-duration model is $850 \mathrm{hPa} / 120 \mathrm{~h}$ in
South and $625 \mathrm{hPa} / 72 \mathrm{~h}$ in North. The explained variance decreases towards higher and lower trajectory end levels and shorter and longer trajectory durations, but not very steeply (Fig. S3). The advantage of the consensus model relative to the best single-level/single duration model is $4 \%$ in South and $7 \%$ in North. For detrended temperature anomalies, the explained variance of the consensus model is about $5 \%$ larger than without detrending, reaching $81 \%$ in both two areas.

The lower part of Table 1 addresses the question whether the third-order regression model with 19 predictor terms could have been replaced by a simpler model. In fact, a first-order model with just three predictors $(x, y, z)$ explains only 5-8\% less, and a second-order model $\left(x, y, z, x^{2}, y^{2}, z^{2}\right.$, $x y, x z, y z)$ only $0.7-1 \%$ less temperature variance than the third-order model. Thus, the difference in the performance of the third- and second-order models is small, and the choice between them also has little impact on the inferred circulation-related temperature trends (not shown). Finally, a third-order model that excludes all terms with $z$ included, and thus only uses the horizontal location of the trajectory start point, also explains $76 \%$ of the detrended monthly temperature variance. The inclusion of the trajectory start level increases the explained variance substantially from May to August, but its effect in autumn and winter is very small (Fig. S4).

The regression maps between trajectory start point and temperature anomalies (Fig. S1) show physically expected geographical patterns. Trajectories originating from south (north) are typically associated with positive (negative) temperature anomalies throughout the year. There is also a pronounced east-west gradient in late fall and winter, with warmer temperatures for trajectories originating from the Atlantic Ocean than from the Eurasian continent. This east-west gradient is reversed in summer but is much weaker. In spring and summer, trajectories descending from upper levels are associated with warmer temperatures than those rising from lower levels (Fig. S2). This may partly reflect the adiabatic warming of descending air, but may also be because descending motion tends to reduce cloud cover and hence increase the solar radiation reaching the surface. In autumn and winter, the dependence of temperature 

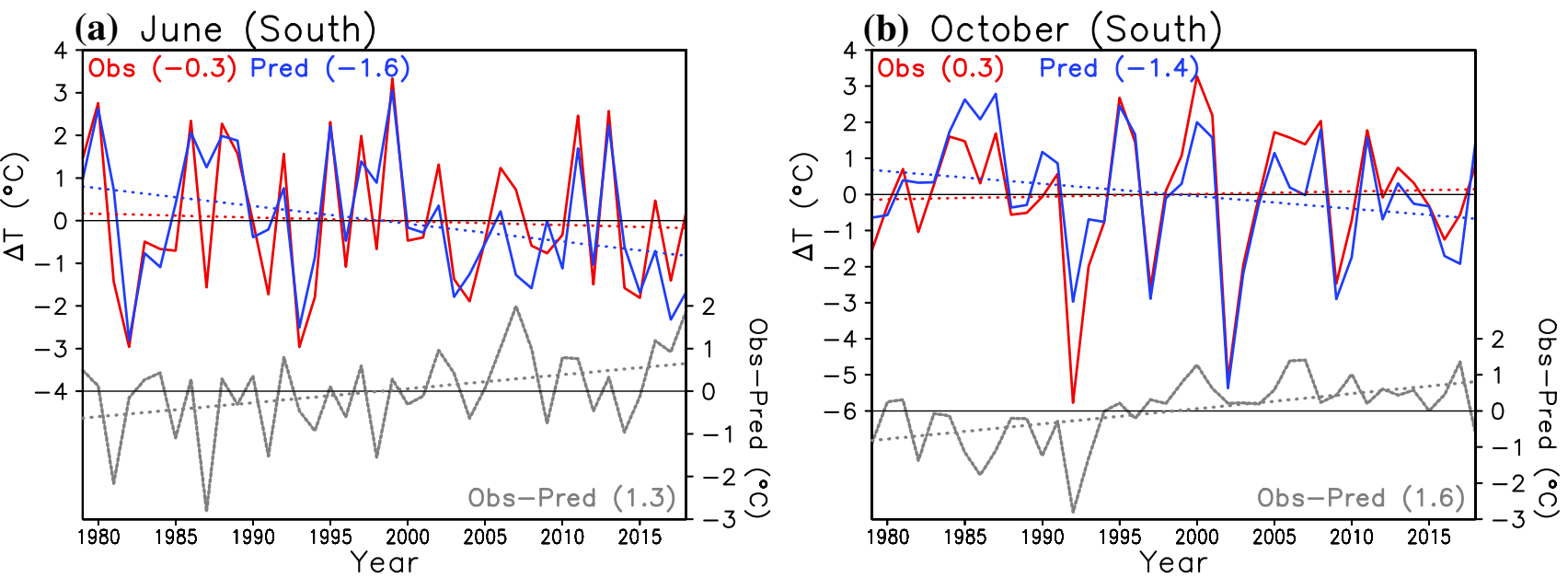

(c) December (South)
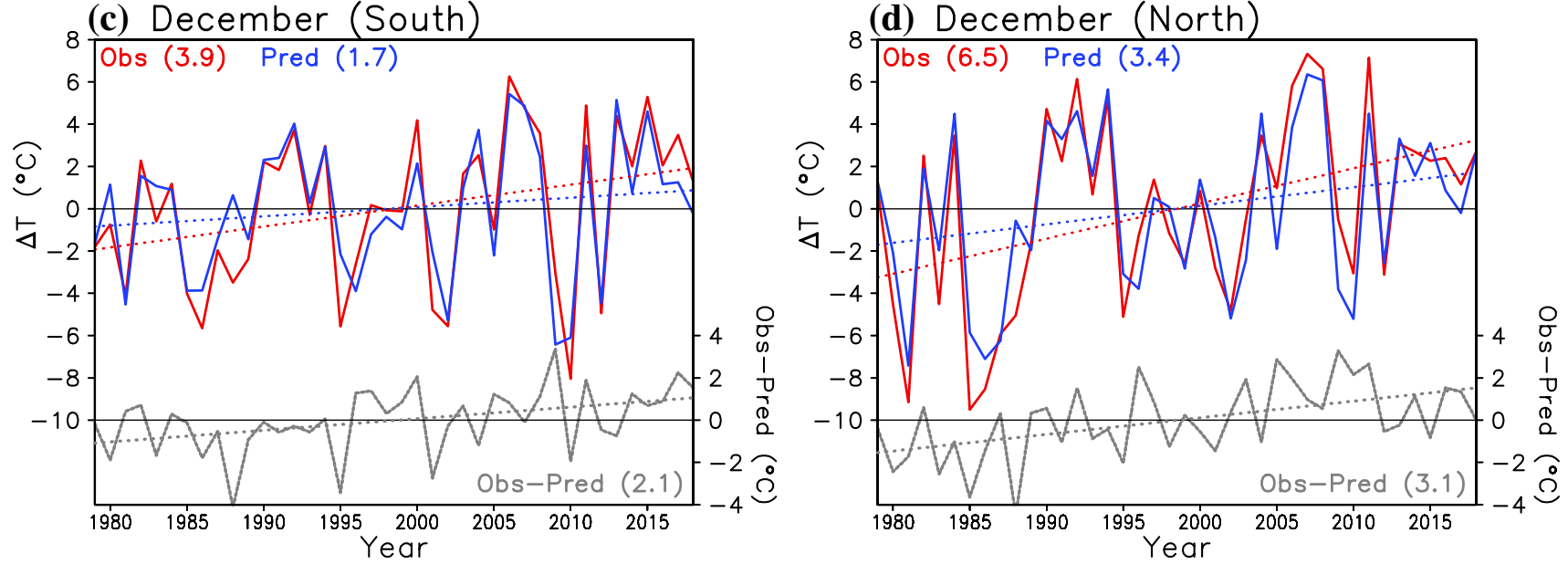

Fig. 5 Time series of temperature anomalies in a June, b October and c December in South, and d December in North. Red: observations; blue: the consensus trajectory-based prediction $\Delta \mathrm{T}_{3}$ from Eq. (4);

gray: the residual $\Delta \mathrm{T}_{\mathrm{obs}}-\Delta \mathrm{T}_{3}$. The least-squares linear trend lines (dotted) and the corresponding 39-year temperature changes (numbers in ${ }^{\circ} \mathrm{C}$ ) are also included

on the vertical motion along the trajectories is much less pronounced.

\subsection{Circulation and temperature change}

Time series of observed monthly mean temperature anomalies and the consensus regression-based predictions $\Delta T_{3}$ (Eq. (4)) are shown in Fig. 5. The differences between these two are also included. Similar diagrams for all 12 months and both the two areas are provided in Figs. S5-S6.

The four cases in Fig. 5 were chosen because of their unexpectedly large or small observed trends (Fig. 3). In all of them, circulation change is found to play an important role. In June in South (Fig. 5a), slight cooling was observed $\left(-0.3{ }^{\circ} \mathrm{C}\right.$ in 39 years), but the trend associated with circulation change is even more negative $\left(-1.6^{\circ} \mathrm{C}\right)$, leaving a residual warming of $1.3{ }^{\circ} \mathrm{C}$. Similarly, the near absence of warming in South in October is due to a markedly negative circulation contribution $\left(-1.4{ }^{\circ} \mathrm{C}\right)$ (Fig. 5b). By contrast,

circulation change has greatly amplified the warming in December, explaining about half of the $3.9^{\circ} \mathrm{C}$ warming in South and the $6.5^{\circ} \mathrm{C}$ warming in North (Fig. 5c, d). As expected, the interannual variability in the residual time series is always smaller than the observed variability, making the signal-to-noise ratio of the warming larger for the residual series.

Figure 6a, b show the observed 39-year monthly temperature trends (red bars) and the circulation-related trend (blue bars) for all 12 months and the two areas. An uncertainty estimate for the circulation-related temperature trends is also shown. This is based on the assumption that, without circulation variability, temperature would have changed linearly with time from 1979 to 2018 . Under this conservative assumption, all the detrended interannual variability in the residual time series $\Delta T_{\text {obs }}-\Delta T_{3}$ in Fig. 5 would result from the inability of the trajectory approach to fully represent the effects of atmospheric circulation. Neglecting interannual 
(a) South: $T$ trends

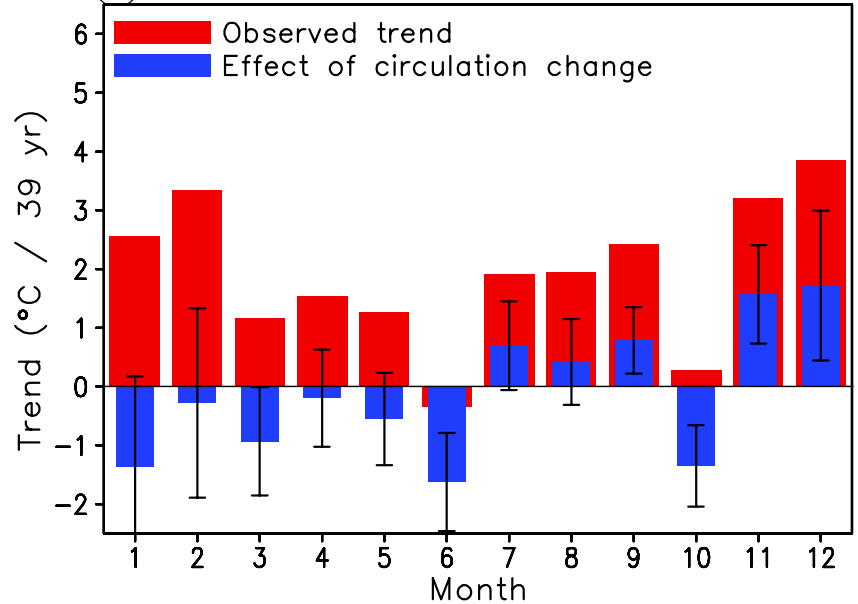

(c) South: Residual trends

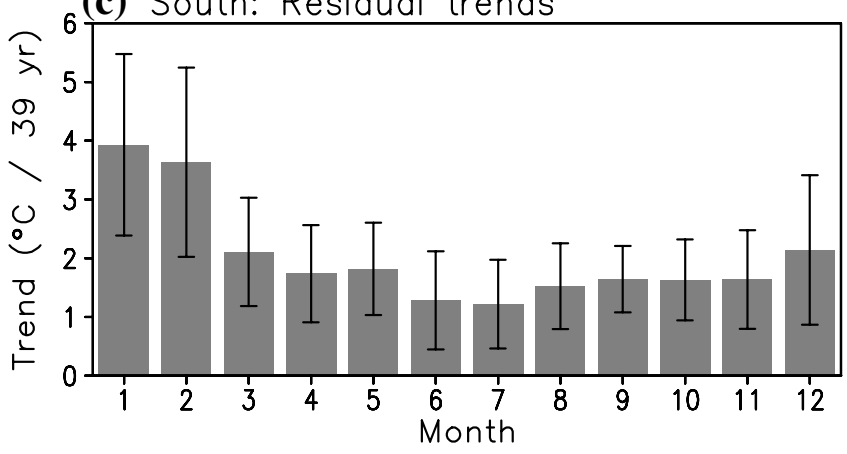

Fig. 6 Linear trends of monthly mean temperature in (left) South and (right) North. In a and $\mathbf{b}$, the red bars show the observed trend and the blue bars the best-estimate circulation-related trend. In $\mathbf{c}$ and

autocorrelation, the standard deviation of the circulationinduced trends was estimated as

$\sigma_{\text {trend }}=\sqrt{\frac{1}{N-2} \frac{\sum_{t=1}^{N} \varepsilon_{t}^{2}}{\sum_{t=1}^{N}\left(t-\frac{N}{2}\right)^{2}}}$

where $\varepsilon_{t}$ are the detrended residuals and $N=40$ is the number of years. The error bars in Fig. 6 span 1.686 standard deviations around the best-estimate trend, representing the 5-95\% confidence interval of the $t$ distribution with 38 degrees of freedom.

In both two study areas, the largest circulation-related warming is found in December and November (Fig. 6a, b). The contribution of circulation change is also significantly positive in September. Conversely, the circulation effect has been significantly negative in March and June, and in South in October. In January, there is a contrast between significant circulation-related warming in North and cooling in South. Also note the wider error bars for the circulation-induced temperature change in Fig. $6 a, b$ in winter than in summer (b) North: $T$ trends

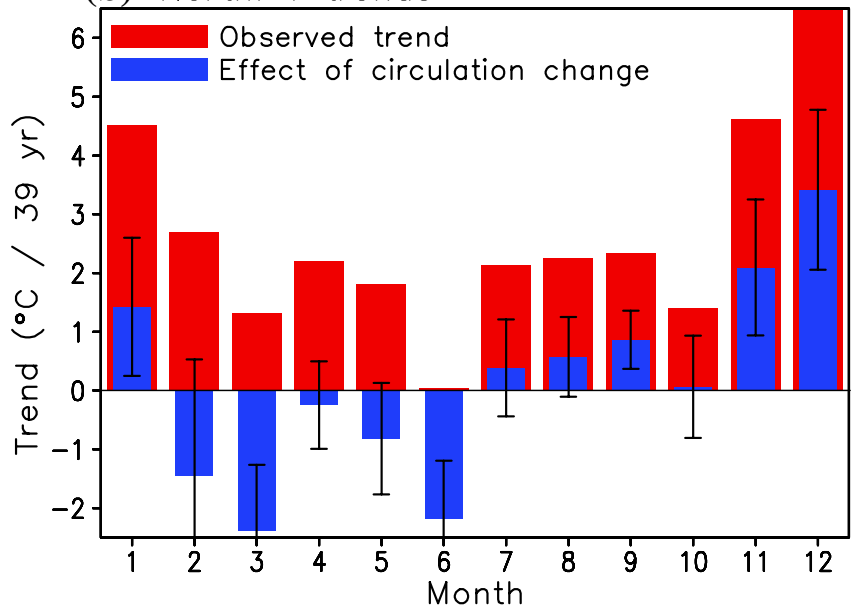

(d) North: Residual trends

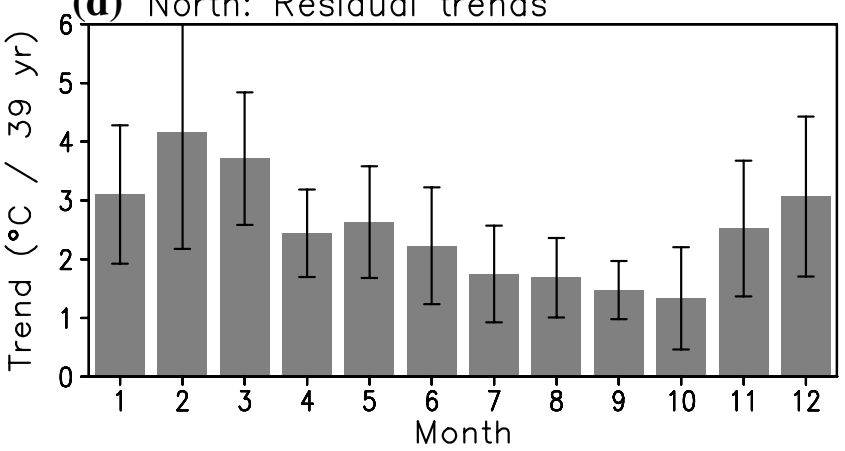

d, the residual trends are shown. The error bars indicate the 5-95\% uncertainty range in the circulation-related trend and the residual trend based on interannual variability

months. Although circulation explains a larger fraction of the observed temperature variability in winter than in summer (Fig. 4), the residual variability is still larger in winter when the observed variability is much larger.

Due to opposing contributions in different months of the year, the effect of circulation change on the annual mean warming in Finland in 1979-2018 is found to be modest: as a best estimate $-0.1{ }^{\circ} \mathrm{C}\left(5-95 \%\right.$ uncertainty range $-0.4{ }^{\circ} \mathrm{C}$ to $\left.0.3{ }^{\circ} \mathrm{C}\right)$ in South and $+0.1{ }^{\circ} \mathrm{C}\left(-0.3{ }^{\circ} \mathrm{C}\right.$ to $\left.0.5{ }^{\circ} \mathrm{C}\right)$ in North.

The error bars in Fig. 6a, b represent the accuracy at which the regression method can quantify the effect of the observed atmospheric circulation change on temperature changes in 1979-2018. They do not tell us whether these circulation-induced temperature changes can be explained by internal variability, or whether they included a forced trend that might be expected to continue in the future. To evaluate these possibilities, internal variability in circulation-induced 39-year temperature trends was estimated by replacing $\varepsilon_{t}$ in (6) with the detrended circulation-induced temperature anomalies. The circulation-induced temperature trends in 1979-2018 were found to be outside the 5-95\% 

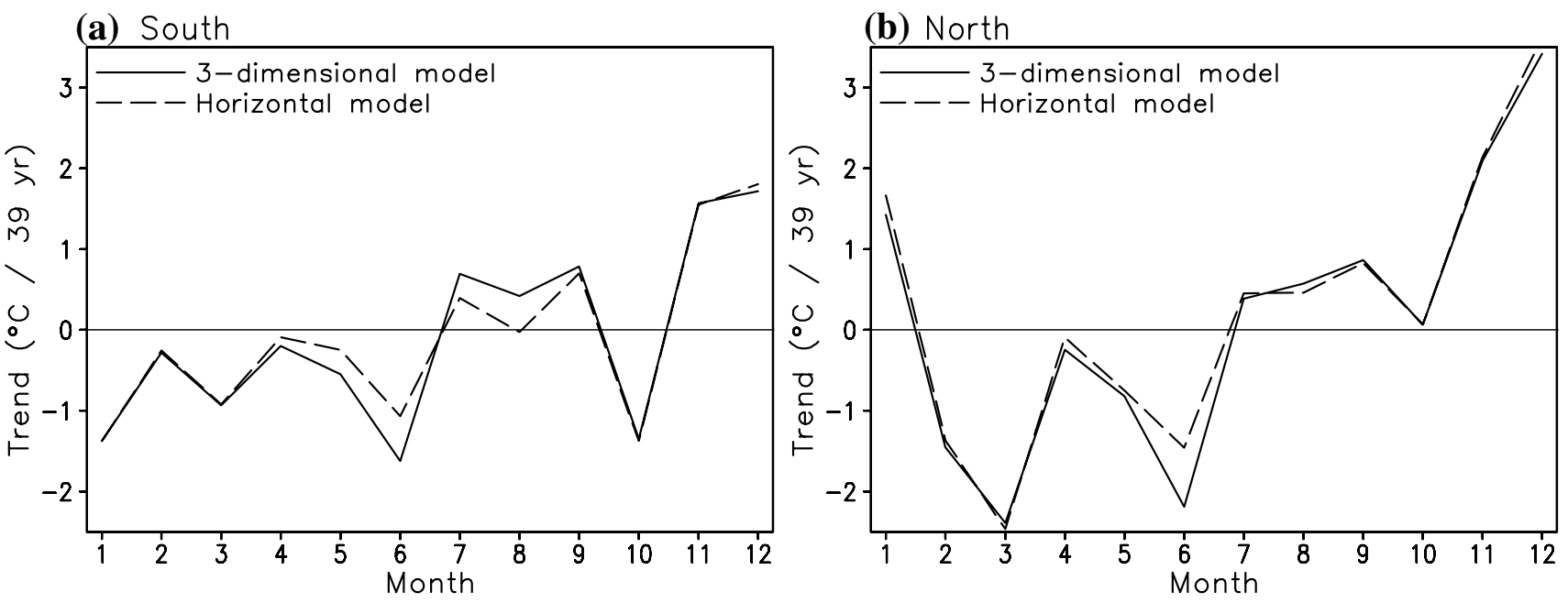

Fig. 7 Circulation-related linear trends of monthly mean temperature in (left) South and (right) North, as calculated with the 3-dimensional (solid line) and the horizontal regression model (dashed line)

(a) June
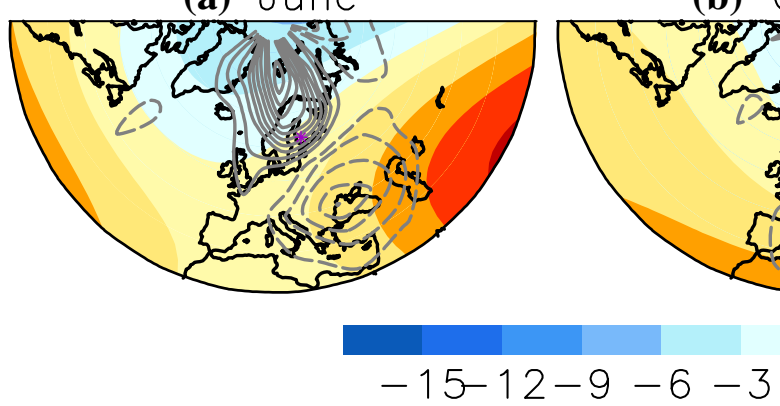

Fig. 8 The contours show the linear trend in the density of trajectory start points from 1979 to 2018 (96-h trajectories ending at $\left(61.5^{\circ} \mathrm{N}\right.$, $24^{\circ} \mathrm{E}, 850 \mathrm{hPa}$ ), contour interval $0.3 \% 10^{-6} \mathrm{~km}^{-2}$ (39 years $)^{-1}$, dashed for negative values, zero contour omitted). To obtain the density trends, the number of trajectory start points was first counted in $10^{\circ}$ lat $\times 15^{\circ}$ lon grid boxes, after which the smth 9 smoothing function

range of internal variability in only three out of the 24 cases: in June in South, and in June and December in North (Fig. S7). Considering this result, it seems unlikely that one can extrapolate these trends to the future.

Subtracting the circulation-related trends from the observed temperature trends gives the residual trends shown in Fig. 6c, d. These residual trends have a much smoother seasonal cycle than the actually observed trends (red bars in Fig. 6a, b), and the residual warming is statistically significant in all 12 months. However, there is a strong seasonal contrast between large warming in winter and smaller warming in summer and early fall. In South, the best-estimate monthly residual trends vary from $1.2{ }^{\circ} \mathrm{C}$ in July to $3.9^{\circ} \mathrm{C}$ in January, in North from $1.3{ }^{\circ} \mathrm{C}$ in October to $4.2{ }^{\circ} \mathrm{C}$ in February. in the GrADS software was applied to further emphasize the general features. The colours indicate the average daily temperature anomaly in South as a function of the trajectory start point based on regression model (1), for 96-h trajectories starting and ending at $850 \mathrm{hPa}$. a June, b October, c December

\subsection{Physical interpretation}

Having analyzed the effect of atmospheric circulation trends on temperature trends, a natural follow-up question is how the circulation actually changed. One complication here is the fact that changes in both the horizontal and the vertical distribution of the trajectory start points might play a role. Furthermore, these two are not independent of each other, since horizontal and vertical motion in the atmosphere tend to be correlated. However, it appears that changes in vertical motion have generally not been very important or, at least, that the relationship between vertical and horizontal motion along the trajectories has not changed substantially. This can be inferred from Fig. 7, which compares the circulation-related temperature trends from the 3 -dimensional 

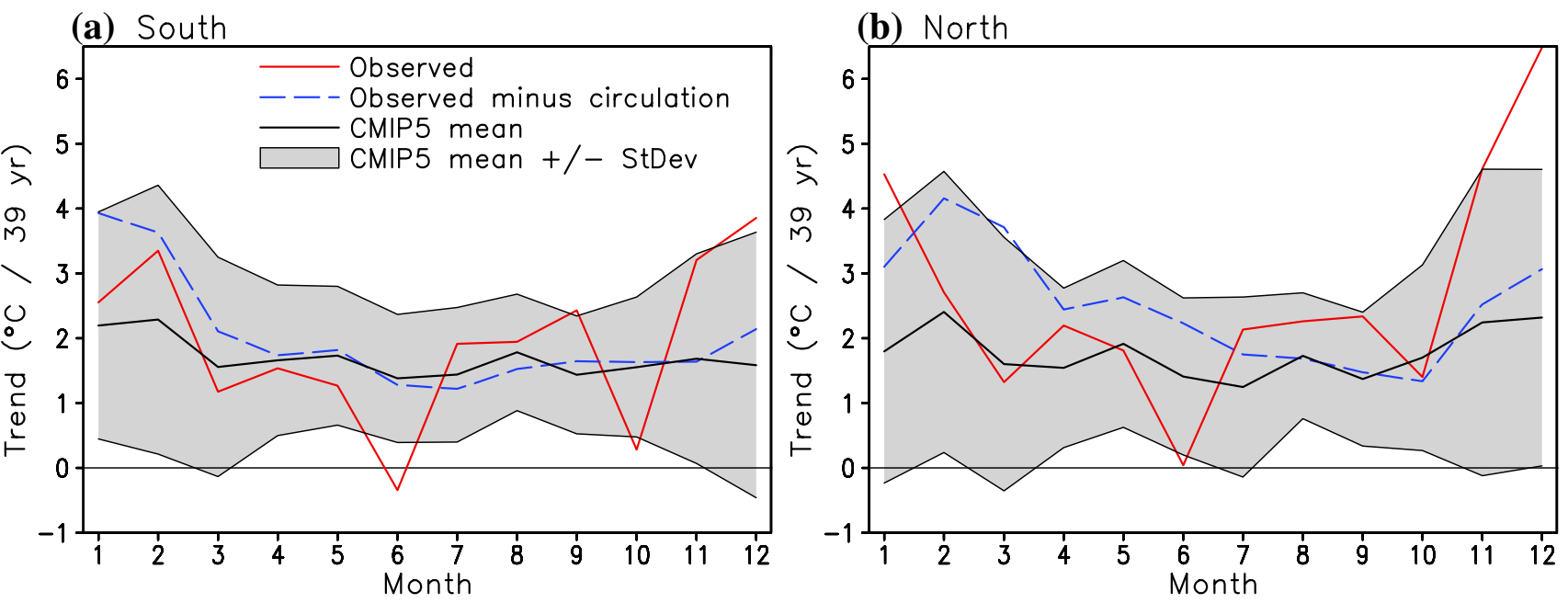

Fig. 9 Linear trends in annual mean temperature in a South and b North from 1979 to 2018. Red: observations from E-OBS; blue: observations minus effect of circulation change; black: CMIP5 multi-model mean; shading: CMIP5 multi-model mean \pm 1 intermodel standard deviation

third-order regression model (19 predictors in (1)) with the horizontal third-order model mentioned in Sect. 3.2 (nine predictors formed of $x$ and $y$ alone). The circulation-related cooling in May and June is larger for the 3-dimensional than the horizontal model, and the same applies to the circulation-related warming in South between July and September. Otherwise, the differences between the two models are small, indicating that it is sufficient to consider the changes in the horizontal position of the trajectory start points.

To exemplify the change in the horizontal start points of the trajectories, we focus in Fig. 8 on the southern area and the same 3 months as in Fig. 5a-c. As it is impractical to show maps for all trajectory durations and end levels, we choose 96-h trajectories ending at $850 \mathrm{hPa}$, this being a representative example. To put the changes in the trajectory start points in context, the colours in Fig. 8 indicate the distribution of average daily temperature anomalies based on the regression model (1). Similar maps for all 12 months are shown in Fig. S8.

In June (Fig. 8a), there has been an increase in trajectories originating from northern Scandinavia and the Nordic Seas, whereas trajectories from the Black Sea region have become less common. This trend, which is indicative of a general increase in northerly flow, is conducive to lower temperatures. The trend pattern in October (Fig. 8b) shows a similar northward shift, with an increasing frequency of trajectories starting from northern Russia and the Arctic Ocean, and a decreasing frequency from southern Europe. In December (Fig. 8c), trajectories far from the west (western North Atlantic and eastern Canada) have become more common, those from nearby areas in northern Russia and the Arctic Ocean less common. Consequently, the circulation-related temperature trend is strongly positive (Figs. 5c and 6a).

\section{Comparison with CMIP5 simulations}

The observed monthly temperature trends in 1979-2018 and the residual trends obtained by subtracting the circulation effect are compared with the CMIP5-simulated temperature trends in Fig. 9. The variation between the CMIP5 models is large. Since local, relatively short trends in monthly mean temperatures are analysed, most of this variation likely results from internal variability in the models, particularly variability in the atmospheric circulation (cf. Deser et al. 2014). The observed temperature trends in both South and North fall within \pm 1 standard deviation of the CMIP5 multimodel mean in eight out of the 12 months, just as expected if the observed and the simulated trends came from the same distribution. None of the observed monthly temperature trends is out of the range of the 42 CMIP5 simulations (not shown). Closest to this comes the cooling in June in South, which is exceeded in two of the 42 models.

Assuming that changes in atmospheric circulation in the CMIP5 models are dominated by internal variability, or that they are forced but model-dependent, their effect on temperature change should be strongly reduced when averaging over the 42 models. If this is true, the multi-model mean temperature change should be only weakly affected by atmospheric circulation change. This also leads to the expectation that the residual warming should fall closer to the multi-model mean warming than the observed warming does. This is indeed the case when considering the 12 months together. In South, the root-mean-square difference from the average CMIP5 monthly temperature trends is $1.12{ }^{\circ} \mathrm{C}$ for the observed trends but only $0.68{ }^{\circ} \mathrm{C}(39 \%$ smaller) for the residual trends. The corresponding numbers for North are $1.71{ }^{\circ} \mathrm{C}, 1.01{ }^{\circ} \mathrm{C}$ and $41 \%$. 
The agreement between the residual warming and the multi-model mean warming is still not perfect. First, the annual mean residual warming exceeds the CMIP5 multimodel mean. The difference is modest in South $\left(2.0{ }^{\circ} \mathrm{C}\right.$ vs. $\left.1.7^{\circ} \mathrm{C}\right)$ but larger in North $\left(2.5^{\circ} \mathrm{C}\right.$ vs. $\left.1.8^{\circ} \mathrm{C}\right)$. Second, the seasonality in the residual warming is larger. The residual warming in winter (December-January-February) exceeds that in summer (June-July-August) by a factor of $2.4\left(3.2{ }^{\circ} \mathrm{C} / 1.3{ }^{\circ} \mathrm{C}\right)$ in South and by a factor of 1.8 $\left(3.4{ }^{\circ} \mathrm{C} / 1.9^{\circ} \mathrm{C}\right)$ in North. The corresponding ratios for the CMIP5 multi-model mean warming are 1.3 in South and 1.5 in North.

Identifying the causes of the model-observation differences remains an important topic for further research. Here we list some of the main possibilities that should be considered.

1. The comparison of the residual warming with the CMIP5 multi-model mean warming is not clean, because the latter may also be to some extent affected by atmospheric circulation change. However, if the findings of Saffioti et al. (2017) extend to the period considered in this study, subtracting the effect of atmospheric circulation change should in fact slightly reduce the multi-model mean winter warming in Scandinavia. This would rather amplify than reduce the difference between models and observations. Ideally, the simulated residual warming should be quantified directly by repeating be trajectory analysis for the CMIP5 simulations, but this is precluded by limitations in data availability.

2. Despite excluding at least most of atmospheric circulation variability, the residual warming might be affected by long-term internal variability in ocean conditions. In particular, there was a shift from the negative to the positive phase of the Atlantic Multidecadal Variability in the 1990s (i.e., the warming of sea surface temperatures in the North Atlantic has exceeded the global average), although its causes are still debated (Sutton et al. 2018). Both model simulations and observations suggest that such a shift should promote warmer conditions in northern Europe, with the largest effect in the northernmost parts of the area (Lyu and Yu 2017). This could thus have amplified the residual warming relative to the CMIP5 multi-model mean warming and might also explain why the difference between these two is larger in northern than southern Finland.

3. Climate models might misrepresent some of the feedbacks that regulate the magnitude of the greenhouse gas induced warming. The fact that the observed residual warming exceeds the CMIP5 multi-model mean warming particularly in winter and in North in spring suggests that snow processes might play a role. The strength of the snow-albedo feedback varies substantially between the CMIP5 models but, based on the variations of temperature and surface albedo during the seasonal cycle, the models do not seem to systematically under- or overestimate this feedback (Qu and Hall 2014). On the other hand, satellite retrievals suggest a decreasing trend in surface albedo in Scandinavia in the years 1982-2015 already before the start of the snow melt period (Anttila et al. 2018). Such an albedo decrease, which is distinct from the traditional snow-albedo feedback, might reflect either changes in vegetation or climate (e.g., less snow in trees in milder winters). To evaluate the potential importance of this issue, comparison between observed and simulated trends in surface albedo would be needed.

4. The effects of some non-greenhouse-gas forcing agents may be inaccurately represented in the CMIP5 simulations. For example, sulphur emissions in Europe as well as upstream in North America have strongly decreased since 1980 (Vestreng et al. 2007; Aas et al. 2019). If climate models underestimated the regional cooling caused by sulphate aerosols, the decrease in sulphur emissions could have induced a larger warming in the real world than in the models (e.g., Wild 2012). Land use changes might also be a factor, but it appears unlikely that they have had a major impact on recent temperature change in Finland. Large areas of peat land have been drained and forested in Finland since the 1920s, but the resulting temperature changes in regional climate model simulations are modest, with a local maximum warming of about $0.4{ }^{\circ} \mathrm{C}$ in April in western Finland (Gao et al. 2014). Moreover, most of this land use change already occurred before the period analyzed in this study.

Warming in Finland started well before the period considered in this paper. Mikkonen et al. (2015) report a bestestimate $2.3{ }^{\circ} \mathrm{C}$ increase in the national mean temperature between the decades 1847-1856 and 2004-2013, using a dynamic linear model approach to isolate the long-term trend underlying the observations. The contrast between winter and summer trends was even larger than that in 1979-2018: a mean warming of $3.3{ }^{\circ} \mathrm{C}$ in December-January-February and $0.9^{\circ} \mathrm{C}$ in June-July-August. Clearly, their study and the present analysis overlap in time periods, and the results are therefore not independent. Still, the findings of Mikkonen et al. (2015) reinforce the conclusion that the warming in Finland has had, this far, a larger winter-to-summer contrast than expected based on the CMIP5 simulations. Before the causes of this difference are understood properly, it is premature to speculate whether the same will also hold in the future. 


\section{Conclusions}

A trajectory-based method was used to diagnose the effect of atmospheric circulation changes on interannual variability and trends of surface air temperature in Finland in the years 1979-2018. The main findings are as follows:

- On the average, $81 \%$ of the detrended interannual variability of monthly mean temperatures is explained by variation in the start points of the trajectories. The explained variance is larger in autumn, winter and early spring than in late spring and in summer.

- Climate in Finland warmed substantially during the study period, with a 39-year annual mean linear trend of $1.9^{\circ} \mathrm{C}$ $\left(2.7^{\circ} \mathrm{C}\right)$ in the southern (northern) Finland study area. These annual mean trends were insignificantly affected by atmospheric circulation change, which provided a best-estimate contribution of $-0.1{ }^{\circ} \mathrm{C}$ in the south and $0.1{ }^{\circ} \mathrm{C}$ in the north.

- Despite their small effect on the annual mean warming, changes in atmospheric circulation substantially modified the seasonal cycle of temperature change in Finland in 1979-2018. In particular, they explain the lack of observed warming in June, the very modest warming in October in southern Finland, and about a half of the very large warming in December.

- The residual trends obtained by subtracting the circulationrelated change from observations are robustly positive in all months of the year and exhibit a smoother seasonal cycle than the actually observed temperature trends.

- The residual temperature trends agree better with the CMIP5 multi-model mean trends than the observed trends do. However, they still exhibit a larger contrast between winter and summer warming than the CMIP5 multi-model mean. In addition, the annual mean residual warming exceeds the CMIP5 multi-model mean warming particularly in northern Finland. Despite several potential candidates, the causes of these differences remain largely unclear.

The current trajectory-based method is also applicable to other areas. Therefore, a natural extension of this study would be a wider analysis of the contribution of atmospheric circulation change to observed temperature changes in different parts of the world. Furthermore, despite the large data needs of the trajectory calculation, an application of this method to at least some climate model simulations would clearly be beneficial.

Acknowledgements Open access funding provided by University of Helsinki including Helsinki University Central Hospital. This work was supported by the Academy of Finland Centre of Excellence in Atmospheric Science-from Molecular and Biological processes to the Global Climate (project 307331). The author also thanks the two reviewers for their comments that helped to improve the original manuscript.

Open Access This article is distributed under the terms of the Creative Commons Attribution 4.0 International License (http://creativeco mmons.org/licenses/by/4.0/), which permits unrestricted use, distribution, and reproduction in any medium, provided you give appropriate credit to the original author(s) and the source, provide a link to the Creative Commons license, and indicate if changes were made.

\section{References}

Aas W et al (2019) Global and regional trends of atmospheric sulfur. Sci Rep 9:953

Anttila K, Manninen T, Jääskeläinen E, Riihelä A, Lahtinen P (2018) The role of climate and land use in the changes in surface albedo prior to snow melt and the timing of melt season of seasonal snow in northern land areas of $40^{\circ}-80^{\circ} \mathrm{N}$ during $1982-2015$. Remote Sens 10:1619

Cattiaux J, Vautard R, Cassou C, Yiou P, Masson-Delmotte V, Codron F (2010) Winter 2010 in Europe: a cold extreme in a warming climate. Geophys Res Lett 37:L20704

Collins M, Knutti R, Arblaster JM, Dufresne J-L, Fichefet T, Friedlingstein P, Gao X, Gutowski WJ, Johns T, Krinner G, Shongwe M, Tebaldi C, Weaver AJ, Wehner M (2013) Long-term climate change: projections, commitments and irreversibility. In: Stocker $\mathrm{T}$ et al (eds) Climate change 2013: the physical science basis. Contribution of working group I to the fifth assessment report of the intergovernmental panel on climate change. Cambridge University Press, Cambridge, pp 1029-1136

Dee DP et al (2011) The ERA-Interim reanalysis: configuration and performance of the data assimilation system. Q J Roy Meteorol Soc 137:553-597

DelSole T, Shukla J (2009) Artificial skill due to predictor screening. J Clim 22:331-345

Deser C, Phillips A, Bourdette V, Teng H (2012) Uncertainty in climate change projections: the role of internal variability. Clim Dyn 38:527-546

Deser C, Phillips AS, Alexander MA, Smoliak BV (2014) Projecting North American climate over the next 50 years: uncertainty due to internal variability. J Clim 27:2271-2296

Deser C, Terray L, Phillips AS (2016) Forced and internal components of winter air temperature trends over North America during the past 50 years: mechanisms and implications. J Clim 29:2237-2258

Fereday D, Chadwick R, Knight J, Scaife AA (2018) Atmospheric dynamics is the largest source of uncertainty in future winter European rainfall. J Clim 31:963-977

Gallagher MR, Shupe MD, Miller NB (2018) Impact of atmospheric circulation on temperature, clouds, and radiation at Summit station, Greenland, with self-organizing maps. J Clim 31:8895-8915

Gao Y, Markkanen T, Backman L, Henttonen HM, Pietikäinen J-P, Mäkelä H, Laaksonen A (2014) Biogeophysical impacts of peatland forestation on regional climate changes in Finland. Biogeosciences 11:7251-7267

Haylock MR, Hofstra N, Klein Tank AMG, Klok EJ, Jones PD, New M (2008) A European daily high-resolution gridded dataset of surface temperature and precipitation. J Geophys Res Atm 113:D20119. https://doi.org/10.1029/2008JD10201

Holmes CR, Woolling T, Hawkins E, de Vries H (2016) Robust future changes in temperature variability under greenhouse gas forcing and the relationship with thermal advection. J Clim 29:2221-2236 
Karpechko AY, Peterson AK, Scaife AA, Vainio J, Gregow H (2015) Skilful seasonal predictions of Baltic Sea ice cover. Environ Res Lett 10:044007

Klein WH, Walsh JE (1983) A comparison of pointwise screening and empirical orthogonal functions in specifying monthly surface temperature from $700 \mathrm{mb}$ data. Mon Weather Rev 111:674-691

Lehner F, Deser C, Terray L (2017) Toward a new estimate of "Time of Emergence" of anthropogenic warming: insights from dynamical adjustment and a large initial-condition model ensemble. J Clim 30:7739-7756

Lyu K, Yu J-Y (2017) Climate impacts of the Atlantic Multidecadal Oscillation simulated in the CMIP5 models: a re-evaluation based on a revised index. Geophys Res Lett 44:3867-3876

Mikkonen S, Laine M, Mäkelä HM, Gregow H, Tuomenvirta H, Lahtinen M, Laaksonen A (2015) Trends in the average temperature in Finland, 1847-2013. Stoch Environ Res Risk Assess 29:1521-1529

Parker DE (2009) Anomalies of central England temperature classified by air source. J Clim 22:1069-1081

Qu X, Hall A (2014) On the persistent spread in snow-albedo feedback. Clim Dyn 42:69-81

Räisänen J (2001) CO2-induced climate change in CMIP2 experiments. Quantification of agreement and role of internal variability. J Clim 14:2088-2104

Räisänen J (2018) Energetics of interannual temperature variability. Clim Dyn. https://doi.org/10.1007/s00382-018-4306-0

Saffioti C, Fischer EM, Scherrer SC, Knutti R (2016) Reconciling observed and modelled temperature and precipitation trends over Europe by adjusting for circulation variability. Geophys Res Lett 43:8189-8198

Saffioti C, Fischer EM, Knutti R (2017) Improved consistency of climate projections over Europe after accounting for atmospheric circulation variability. J Clim 30:7271-7291
Selten FM, Branstator GW, Dijkstra HA, Kliphuis M (2004) Tropical origins for recent and future Northern Hemisphere climate change. Geophys Res Lett 31:L21205

Smoliak BV, Wallace JM, Lin P, Fu Q (2015) Dynamical adjustment of the Northern Hemisphere surface air temperature field: methodology and application to observations. J Clim 28:1613-1629

Sutton RT, McCarthy GD, Robson J, Sinha B, Archibald AT, Gray LJ (2018) Atlantic multidecadal variability and the U.K. ACSIS program. Bull Am Meteorol Soc 99:415-425

Taylor KE, Stouffer RJ, Meehl GA (2012) An overview of CMIP5 and the experiment design. Bull Am Meteorol Soc 93:485-498

Tebaldi C, Arblaster JM (2014) Pattern scaling: Its strengths and limitations, and an update on the latest model simulations. Clim Change 122:459-471

Toumi R, Hartell N, Bignell K (1999) Mountain station pressure as an indicator of climate change. Geophys Res Lett 26:1751-1754

van Vuuren DP et al (2011) The representative concentration pathways: an overview. Clim Change 109:5-31

Vestreng V, Myhre G, Fagerli H, Reis S, Tarrasón L (2007) Twenty-five years of continuous sulphur dioxide emission reduction in Europe. Atmos Chem Phys 7:3663-3681

Wild M (2012) Enlightening global dimming and brightening. Bull Am Meteorol Soc 93:27-37

Publisher's Note Springer Nature remains neutral with regard to jurisdictional claims in published maps and institutional affiliations. 